NASA/TM-1999-208838

\title{
Solid Phase Luminescence of Several Rare Earth Ions on Ion-Exchange Films
}

Stephen P. Tanner

University of West Florida, Pensacola, Florida

Kenneth W. Street, Jr.

Glenn Research Center, Cleveland, Ohio 
Since its founding, NASA has been dedicated to the advancement of aeronautics and space science. The NASA Scientific and Technical Information (STI) Program Office plays a key part in helping NASA maintain this important role.

The NASA STI Program Office is operated by Langley Research Center, the Lead Center for NASA's scientific and technical information. The NASA STI Program Office provides access to the NASA STI Database, the largest collection of aeronautical and space science STI in the world. The Program Office is also NASA's institutional mechanism for disseminating the results of its research and development activities. These results are published by NASA in the NASA STI Report Series, which includes the following report types:

- TECHNICAL PUBLICATION. Reports of completed research or a major significant phase of research that present the results of NASA programs and include extensive data or theoretical analysis. Includes compilations of significant scientific and technical data and information deemed to be of continuing reference value. NASA's counterpart of peerreviewed formal professional papers but has less stringent limitations on manuscript length and extent of graphic presentations.

- TECHNICAL MEMORANDUM. Scientific and technical findings that are preliminary or of specialized interest, e.g., quick release reports, working papers, and bibliographies that contain minimal annotation. Does not contain extensive analysis.

- CONTRACTOR REPORT. Scientific and technical findings by NASA-sponsored contractors and grantees.
- CONFERENCE PUBLICATION. Collected papers from scientific and technical conferences, symposia, seminars, or other meetings sponsored or cosponsored by NASA.

- SPECIAL PUBLICATION. Scientific, technical, or historical information from NASA programs, projects, and missions, often concerned with subjects having substantial public interest.

- TECHNICAL TRANSLATION. Englishlanguage translations of foreign scientific and technical material pertinent to NASA's mission.

Specialized services that complement the STI Program Office's diverse offerings include creating custom thesauri, building customized data bases, organizing and publishing research results ... even providing videos.

For more information about the NASA STI Program Office, see the following:

- Access the NASA STI Program Home Page at http://www.sti.nasa.gov

- E-mail your question via the Internet to help@sti.nasa.gov

- Fax your question to the NASA Access Help Desk at (301) 621-0134

- Telephone the NASA Access Help Desk at (301) 621-0390

- Write to: NASA Access Help Desk NASA Center for AeroSpace Information 7121 Standard Drive Hanover, MD 21076 
NASA/TM-1999-208838

\section{Solid Phase Luminescence of Several Rare Earth Ions on Ion-Exchange Films}

Stephen P. Tanner

University of West Florida, Pensacola, Florida

Kenneth W. Street, Jr.

Glenn Research Center, Cleveland, Ohio

National Aeronautics and

Space Administration

Glenn Research Center 


\section{Acknowledgments}

The authors would like to thank the NASA Glenn Research Center Director's Discretionary Fund for the initial funding of this research and the ASEE summer faculty fellowship program for summer support (SPT). The authors are grateful to Phillip P. Jenkins, Essential Research Inc., for acquiring spectra on the laser luminescence spectrometer; Judith V. Auping, NASA Glenn Research Center, for assistance with the Aminco spectrofluorometer; and the Perkin-Elmer Corp. for their assistance and use of their LS-50b spectrofluorometer.

Trade names or manufacturers' names are used in this report for identification only. This usage does not constitute an official endorsement, either expressed or implied, by the National Aeronautics and Space Administration.

Available from

NASA Center for Aerospace Information

National Technical Information Service 7121 Standard Drive 5285 Port Royal Road Hanover, MD 21076

Price Code: A03 Springfield, VA 22100

Price Code: $\mathrm{A} 03$ 


\title{
SOLID-PHASE LUMINESCENCE OF SEVERAL RARE EARTH IONS ON ION-EXCHANGE FILMS
}

\author{
Stephen P. Tanner \\ University of West Florida \\ Department of Chemistry \\ 11000 University Parkway \\ Pensacola. Florida 32514 \\ Kenneth W. Street, Jr. \\ National Aeronautics and Space Administration \\ Glenn Research Center \\ Cleveland, Ohio 44135
}

\begin{abstract}
SUMMARY
The development and characterization of a novel ion-exchange film for solid-phase fluorometry and phosphorimetry is reported. This new cation-exchange material is suitable for spectroscopic applications in the ultraviolet and visible regions. It is advantageous because it, as a single entity, is easily recovered from solution and mounted in the spectrofluorometers. After preconcentration on the film, the luminescence intensity of lanthanide ions is several orders of magnitude greater than that of the corresponding solution, depending on the volume of solution and the amount of film. This procedure allows emission spectral measurements and determination of lanthanide ions at solution concentrations of $<5 \mu \mathrm{g} /$. The film may be stored for subsequent reuse or as a permanent record of the analysis. The major drawback to the use of the film is slow uptake of analyte due to diffusion limitations.
\end{abstract}

\section{INTRODUCTION}

The determination of metal ions in solution is typically performed by one of the atomic spectroscopies, such as atomic absorption (AAS) or inductively coupled argon plasma emission (ICAP) because of the ease. high sensitivity, and selectivity of these techniques. A limitation of these techniques is the requirement for expensive instrumentation, which is typically limited to metal ion analyses. Ultraviolet/visible spectrophotometry (UV-Vis) has been used for many decades because it is an inexpensive technique, even though it suffers from low sensitivity and selectivity. Shortcomings of spectrophotometry have been minimized by the development of chromophoric reagents in combination with simple separation techniques. Nonetheless, the general sensitivity of the spectrophotometric methods does not compare favorably to the atomic spectroscopies.

To improve the sensitivity and detection limits of the spectrophotometric technique, solid-phase spectrophotometry (SPS) was developed and a large number of methods have been reported with limits of detection rivaling those of the atomic spectroscopies. In SPS, the additional sensitivity is gained by preconcentrating the analyte on a small quantity of ion-exchange material, which serves as the spectroscopic medium. The selectivity and sensitivity are enhanced by the use of chromophoric reagents as is done in conventional spectrophotometry. The disadvantage to this technique is that many of the ion-exchange resins employed are highly absorbing in the regions of interest and are highly scattering at all wavelengths, even when combined with refractive index matching solvents in short pathlength cells. The scattering problem has been largely overcome with the development of a new ionexchange material (IEM) (ref. 1). This cationic IEM can be prepared as a thin transparent film that when coupled with water allows for spectrophotometric determinations throughout the visible and the majority of the ultraviolet region. Thin films of this material, which effectively remove metal cations from aqueous solution, were originally developed as insulators for separating the metallic plates in alkali voltaic cells used in space vehicles (refs. 2 to 4 ). Further development of these materials resulted from the National Aeronautics and Space Administration's efforts to save the environment and to transfer commercially viable technology to industry. The current version of the IEM film has several advantages over commercial resins in addition to optical transparency (ref. 1). In many resins, $\mathrm{Ca}^{2+}$, 
normally present in natural waters, competes with the metal ions for sites on the resin, thus rendering the resin beads less effective. One advantage of this new IEM is that it is more effective in the $\mathrm{Ca}^{2+}$ form than in either the acid or $\mathrm{Na}^{+}$forms.

While the first analytical applications of the IEM employed solid-phase spectrophotometry, luminescence determinations generally yield additional sensitivity and selectivity for those analytes that fluoresce or phosphoresce. Analytes that have no inherent luminescence can also be made to luminesce by the addition of fluorophoric reagents as has been done for spectrophotometric analysis. Typically, luminescence methods have limits of detection that are at least 3 orders of magnitude below spectrophotometry. It is therefore logical that the SPS technique be extended to solid-phase fluorometry (refs. 5 to 11 ). Some of the same problems of absorptivity and light scattering by the ion-exchange media employed in SPS are minimized by using SPF; however, many of the resins tend to be highly luminescent. which introduces another drawback. A number of methods have been developed for the determination of lanthanide ions by SPF techniques after preconcentration on polymeric matrices. Lanthanide trifluoroacetylacetonate complexes are sorbed by polymers functionalized by such groups as tetrazole, triazole, imidazole, and diaza crown ethers (ref. 12). A similar procedure uses polymethylmethacrylate to preconcentrate the lanthanide ions (ref. 13). Both methods employ trifluoroacetylacetone to enhance the luminescence and require filtration to isolate the polymeric matrix prior to fluorescence measurements on the solid substrate. In this paper we present initial findings on the use of ion-exchange films as a preconcentration medium for SPF for use with metal ions that have inherent luminescence.

\section{EXPERIMENTAL}

Four different instruments were used to measure the emission spectra of lanthanide ions. Preliminary spectra were taken on a Baird Atomic Model FC 100 Fluorichord Spectrofluorometer with slits manually adjusted to optimize signal intensity and resolution. Fluorescence and phosphorescence emission spectra were recorded on either a Perkin-Elmer Model LS-50b Spectrofluorometer or an Aminco AB 2 Luminescence Spectrometer. Instrumental conditions are discussed in the text and in figure captions. The laser luminescence spectra were acquired on an instrument that was constructed in-house and consisted of a Coherent Inova 70 Argon lon Laser operated at 10 MW mm$~^{-2}$ at the $488 \mathrm{~nm}$ line coupled to a $1.25 \mathrm{~m}$ Spex 1269 monochromator fitted with a liquid-nitrogen-cooled Spex Spectrum 1 CCD array. The spectra of solutions in all instruments were recorded in 1-by $1-\mathrm{cm}$ quartz fluorescence cells. Spectra of films were taken in a triangular cell filled with deionized water such that the film was at an angle of $45^{\circ}$ with respect to excitation and emission slits for the Fluorichord. In other instruments, front surface attachments provided by the vendors were used for film measurements. For the laser fluorometer, the samples were held in the laser beam using a clamp.

Stock solutions, $1000 \mathrm{mg} / \mathrm{l}$ in lanthanide ions: Sm (Alpha), $\mathrm{Tb}$ (Aldrich), and Gd (SCM) were prepared from the corresponding hydrated chlorides. Europium chloride was prepared by dissolving the oxide (Johnson Matthey) in excess concentrated hydrochloric acid, evaporating to near dryness, and redissolving in deionized water. This process was repeated until the resulting solution reached a $\mathrm{pH}$ of 6 . The solutions were standardized by passing aliquots through a column of Dowex 50W-X8 (J.T. Baker) resin in acid form and titrating the liberated acid with standard sodium hydroxide. The concentrations were checked by ICAP (Perkin-Elmer Plasma 40) calibrated with standards prepared by serial dilution of Spex $1000 \mathrm{mg} /$ inductively coupled argon plasma (ICAP) standards. Uranyl nitrate hexahydrate (Mallincrodt, analytical reagent grade) was dissolved in deionized water ( $1000 \mathrm{mg} / \mathrm{l}$ ) and determined gravimetrically with 8-hydroxyquinoline (Fisher, Certified Reagent). The $1000 \mathrm{mg} / \mathrm{l} \mathrm{Ce}{ }^{3+}$ standard was prepared from $\mathrm{CeCl}_{3} \bullet 7 \mathrm{H}_{3} \mathrm{O}$ (Aldrich) in deionized water and dilutions were calibrated by ICAP. All other standard solutions were prepared by serial dilution with deionized water or analytical reagent-grade buffers or acids as described. Other stock solutions or reagents were prepared by dissolving analytical reagent-grade metal salts in acids or buffers prepared from analytical reagent-grade chemicals and deionized water.

In all experiments, the $\mathrm{pH}$ of solutions was monitored on a Corning Model $130 \mathrm{pH}$ meter equipped with combination $\mathrm{pH}$ and automatic temperature-correcting electrodes and was calibrated with $\mathrm{pH} 4$ and 7 buffers. In each series of solutions, the ion-exchange material (IEM) film was cut from the same larger piece to the dimensions of $\sim 1$ by $3 \mathrm{~cm}$ and trimmed to bring the weight to within $\pm 0.2 \mathrm{mg}$ of the specified weight. For solutions of metals in the parts per million range, the standard to be equilibrated with film was brought to a typical volume of $200 \mathrm{ml}$ and the $\mathrm{pH}$ adjusted with the minimal volume of acid or base and stirred for at least $24 \mathrm{hr}$ with the film. For standards of metals in the parts per billion range, the solution was treated as above using a volume of 1.0 liter and an 
equilibration time of $48 \mathrm{hr}$. In the Tb experiment with o-phenanthroline. $12.5 \mathrm{ml}$ of o-phenanthroline hydrochloride (Fisher, Certified Reagent), 0.3 percent in deionized water, was added to the standard prior to $\mathrm{pH}$ adjustment to 6.5 . followed by addition of $40 \mathrm{mg}$ film. Other conditions employed are mentioned where appropriate.

The ion-exchange film material consists of polyacrylic acid entangled into a matrix consisting of insolubilized or further cross-linked polyvinyl alcohol. The preparation of the acid form of the film was as in the literature (ref. 14). In these experiments, the film was converted to the calcium form with calcium hydroxide.

\section{RESULTS AND DISCUSSION}

The IEM film is inactive in the acid form and required conversion to the salt form with the corresponding hydroxide. In the case of sodium. the film swells and tends to break apart. The calcium form of the film is preferred for a variety of reasons. First, the calcium form of the film shrinks, which indicates that the calcium ion tends to cross-link between two ion-exchange sites, and produces a more rugged material. While the kinetics of analyte ion uptake appear to be slower with the calcium film, the equilibrium solution concentration of analyte over the calcium resin is always lower for multivalent ions.

Many of the lanthanide ions serve as model analytes for testing the behavior of ion-exchange materials as media for SPF. The ions $\mathrm{Tb}^{3+}, \mathrm{Eu}^{3 *}, \mathrm{Gd}^{3 *}$, and $\mathrm{Sm}^{3+}$ all have adequate luminescence, different excitation and emission wavelengths, and a variety of lifetimes to serve as test analytes for SPF. Earlier reports of luminescence of $\mathrm{Tb}^{1+}$ on ion-exchange media (refs. 15 and 16) and the characterized lifetime behavior of the coordinated $\mathrm{Tb}^{3+}$ ion (ref. 17) prompted our use of this ion to characterize the ion-exchange material. Other luminescent ions used in this study included $\mathrm{Ce}^{3+}$ and $\mathrm{UO}_{2}^{2+}$.

The luminescence decay rate for the $\mathrm{Tb}^{3+}$ ion in solution is well characterized, and numerous applications appear in the literature that apply this ion as a probe of the mechanism of coordination of ligands (ref. 17). Terbium has a coordination number of 9 , and the first-order decay rate constant for luminescence emission is a function of the number of coordination sites occupied by water ligands. We have long suspected that the mechanism by which this ion-exchange film operates includes both an ion-ion attraction mechanism and a chelation mechanism for ions that are favorably chelated by carboxylate ligands. The first order decay rate constant for $\mathrm{Tb}^{2+}$ on $\mathrm{P}-81$ ionexchange filter paper (ref. 15) was found to be $2.2 \mathrm{~ms}^{-1}$, the same as that of the $\mathrm{Tb}$ ion in aqueous solution, which indicates coordination to 9 water molecules. This is interpreted as a strictly ion-ion attraction mechanism for the $\mathrm{Tb}$ bound to the P-81 cation-exchange filter paper reported earlier. By contrast, the new ion-exchange film loaded with $\mathrm{Tb}^{3+}$ and $\mathrm{Gd}^{3+}$ ions consistently produced a first order decay rate constant of $0.84 \pm 0.03 \mathrm{~ms}^{-1}$ independent of the $\mathrm{Gd}$ concentration. This value suggests that the $\mathrm{Tb}$ ion on this media is coordinated to only 3 water molecules (refs. 17 and 18). The resulting loss of 6 water molecules is interpreted as an indication that the ion-exchange film also acts as a chelating exchanger for this ion.

The spectra in figure 1 demonstrate the power of the solid-phase luminescence technique. It is clear that, under the conditions employed for obtaining the spectra, a $10 \mu \mathrm{g} / \mathrm{l}$ solution shows no spectral characteristic of the $\mathrm{Tb}^{3+}$ ion; however, when the $\mathrm{Tb}$ ion is preconcentrated on a small quantity of IEM film, the spectral intensity obtained is considerably greater than that obtained from a $10 \mathrm{mg} / \mathrm{l}$ solution. This indicates a 4100 -fold spectral enhancement in signal for the band at $488 \mathrm{~nm}$ and an enhancement of 4800 for the $545 \mathrm{~nm}$ band over the intensity that would be observed in the original solution. The enhancement is a result of both the increased concentration and the higher emission intensity that result from the displacement of coordinated water molecules by the carboxylate groups of the ion-exchange polymer, as discussed above. This difference in enhancement of the 488- and 545-nm bands may be caused by the change in environment of the $\mathrm{Tb}$ in combination with the hypersensitivity of the 488 $\mathrm{nm}{ }^{5} \mathrm{D}_{4} \rightarrow{ }^{7} \mathrm{~F}_{6}$ transition. It is possible to achieve even larger enhancements, as described below.

All fluorescence spectra on ion-exchange films contained a large luminescence background regardless of excitation wavelength and emission range employed. Several of the instruments used in these investigations were capable of temporal discrimination, i.e., exciting with a short pulse of radiation and only collecting luminescence emission in a time window that does not overlap the excitation pulse, conditions which are typically associated with phosphorescence. When using an emission collection window temporally separated from the excitation pulse. all background from the film was eliminated, which indicated that the background interference from this media is a short-lived fluorescence rather than a longer lived phosphorescence. All the lanthanides studied have long-lived luminescence, which allows for collection of excellent spectra by using a short delay between excitation and 
luminescence collection (figs. 2 and 3). The source of the background luminescence remains unidentified and is probably the result of polyvinyl alcohol degradation during the drying step, which causes a slight yellowing of the film.

Several experiments that use high concentrations of metals did not produce a linear correlation between luminescence intensity and concentration. Metal-ion mixtures were tested to determine if irreproducible metal-ion uptake was the problem and if it could be minimized by using the internal standard method normalizing the $\mathrm{Gd}^{3+}$ luminescence intensity at $310 \mathrm{~nm}$ to either of the Tb peaks at 488 or $545 \mathrm{~nm}$. Films prepared by equilibrating in $100 \mathrm{ml}$ of a mixture of $\mathrm{Gd}(3,9$, or $12 \mathrm{mg} / \mathrm{l})$ and $\mathrm{Tb}(5 \mathrm{mg} / \mathrm{l})$ were prepared and emission spectra acquired to see whether adequate calibration curves could be constructed. Spectra for the 3,9 . and $12 \mathrm{mg} / \mathrm{l} \mathrm{Gd} / 5-\mathrm{mg} / \mathrm{T} \mathrm{Tb}$ mixtures are shown in figure 4. From these spectra it is apparent that the emission intensity of the Tb is not constant. In addition. the emission intensity versus the concentration of $\mathrm{Gd}$ is nonlinear. The increase in intensity is a consequence of two factors: (a) the higher concentration of Tb in the IEM film as compared to the solution concentration, and (b) the longer fluorescent lifetime resulting from the displacement of coordinated water molecules by the carboxylate groups of the ion-exchange polymer, as discussed in the previous paragraph. The difference in the enhancement of the 488- and 545-nm emission lines may be a result of the change of the coordination environment in combination with the hypersensitivity of the $488 \mathrm{~nm}^{5} \mathrm{D}_{4} \rightarrow \mathrm{F}_{6}$ transition. Gd is reported to be a sensitizer for the hypersensitive transition, which would involve a change in the rate constant for decay of Gd. This is not what was observed; instead, the rate constant was determined to be $0.27 \pm 0.03 \mathrm{~ms}^{-1}$ for all samples. Furthermore, an internal standard plot of the Gd intensity normalized by the Tb intensity versus concentration was linear, which would not be expected if energy transfer was involved (see table I).

Because of our past experience with solid-phase spectrophotometry (SPS) producing linear calibration curves with this film (ref. 1), it was suspected that the nonlinearity observed in the SPF was due to the high loading of metals on the film and that lowering the amount of loading would eliminate the problem. Subsequent calibration curves prepared by extracting Tb from 200.75 , and $25 \mu \mathrm{g} / \mathrm{l}$ standards on $75 \mathrm{mg}$ IEM produced a linear relationship with a correlation coefficient of 0.99 (fig. 5). A 10 and $5 \mu \mathrm{g} / 1$ standard were also extracted but with incomplete recovery from the $10 \mu \mathrm{g} / \mathrm{l}$ and negligible recovery from the $5 \mu \mathrm{g} / \mathrm{l}$ standard. All spectra acquired had excellent $\mathrm{S} / \mathrm{N}$, which indicated that $\mathrm{Tb}$ luminescence from these low concentration standards was not lost in the noise, but that the $\mathrm{Tb}$ was not quantitatively extracted by the film. In other words, the limit of detection for this type of SPF methodology will not be determined by instrumental constraints, but by the chemical equilibrium associated with the ionexchanger and its affinity for the analyte involved. It is not possible to use this data to calculate the equilibrium constant for the system because the solution $\mathrm{Ca}^{2+}$ concentration was not determined at equilibrium, and calculated concentrations using the normal assumptions (calculated $5 \mu \mathrm{M}$ ) are speculative because of the ubiquitous nature of $\mathrm{Ca}$ contamination. Nonetheless, it is possible to calculate the value for $\mathrm{K}_{\mathrm{D}}$ (the ratio of the concentration of $\mathrm{Tb}$ in the resin to the concentration of $\mathrm{Tb}$ in solution), which is $5.7 \times 10^{3}$ for the $10 \mu \mathrm{g} / \mathrm{l}$ solution and considerably larger for the higher concentrations. These numbers in combination with recovery values presented in table II are consistent with a highly favorable process, which implies that SPF method development for the trace analysis of $\mathrm{Tb}$ (and other trivalent ions) in a variety of samples should be feasible.

Neutral ligands have been used to overcome the limitation of ion-exchange equilibrium on the uptake of metal ions (ref. 19). Ligands such as o-phenanthroline form cationic complexes with metals, which facilitates their uptake into the film at low concentrations, by a liquid-liquid extraction mechanism between the hydrophobic film and the hydrophobic ligand portion of the complex. Figure 6 demonstrates that even at $2.5 \mu \mathrm{g} / \mathrm{l}$, the film quantitatively recovers $\mathrm{Tb}$ in the presence of the ligand. It was hoped that the highly absorbing o-phenanthroline would enhance luminescence of Tb by energy transfer from the ligand to the metal, that is, $L^{*}+M \rightarrow M^{*}+L$. Unfortunately, no enhanced luminescence was observed, and the curve becomes nonlinear at higher concentration. This is probably due to the high absorptivity of the $\pi \rightarrow \pi^{*}$ transition in the ligand, which causes primary inner filtering.

The ion-exchange material developed is a weak acid form of exchanger, and consequently, it is inactive below $\mathrm{pH} 3$ to 5 , depending on the ion involved. As a result, uptake studies were performed in the $\mathrm{pH} 5.5$ to 6.5 range wherever possible. Above $\mathrm{pH} 7$ the metal ions typically form insoluble hydroxy species or continue hydroxide uptake to form anionic complexes, neither of which are taken up by this film. The film is effective in removing a variety of metals as evidenced by the percent of recovery of metals onto the film as presented in table II. One of the major difficulties in taking up metals that form oxy-cations like uranium is that the chemistry is a complex function of $\mathrm{pH}$. Uranium (VI) exists in acidic medium as the $\mathrm{UO}_{2}{ }^{2+}$ ion. As the $\mathrm{pH}$ rises, the dimeric species $\mathrm{U}_{2} \mathrm{O}_{4}{ }^{2+}$ and higher order aggregates as well as hydroxy complexes like $\mathrm{UO}_{2}(\mathrm{OH})^{+}$and $\left(\mathrm{UO}_{2}\right)_{2}(\mathrm{OH})_{2}{ }^{2+}$ become prevalent 
(refs. 20 and 21). The emission spectra in figure 7 indicate how the solution behavior changes the spectral features. In acidic medium, phosphate tends to complex strongly to uranium. which produces an intense emission spectrum with well-resolved bands in the 450 to $550 \mathrm{~nm}$ region. As the $\mathrm{pH}$ rises in the absence of phosphate, the spectral features become less resolved. Figure 7 (a) is the spectrum of the $\mathrm{UO}_{2}{ }^{2+}$ recovered from the IEM in a small volume of sulfuric-phosphoric acid medium, which compares favorably to emission spectra in the literature (ref. 22). The spectra produced from IEM films equilibrated with dilute $\mathrm{UO}_{2}{ }^{2+}$ solutions at $\mathrm{pH} 6.3$ have readily identifiable bands that correlate well with the solution spectra in acidic-phosphate medium. The spectra of films equilibrated with higher uranium concentrations at $\mathrm{pH} 6.3$ and 6.6 have lost all fine structure and collapse into a single broad band spanning the emission envelope (fig. 8). Past experience has shown that common metals are readily recovered from this film by acid stripping. This is also the case for oxy-cations like $\mathrm{UO}_{2}^{2+}$ (table II, footnote a). At this time it is not anticipated that this ion-exchange film will be useful for development of SPF methodology for use with uranium. despite the modest affinity of the film for species that contain Uranium (VI) (table II).

Prior to studies indicating that the limit of detection for Ln's in this film would be equilibrium limited, a series of experiments were performed on a laser luminescence spectrometer. Excitation that uses the high power from the laser generically excites $\mathrm{Tb}, \mathrm{Eu}$, and $\mathrm{Sm}$, and all that have readily distinguishable emission spectra should allow for their simultaneous determination (fig. 9). The background absent in the Tb spectrum is attributed to the highly efficient excitation of the Tb, which has a spectroscopic transition $\left({ }^{7} \mathrm{~F}_{6} \rightarrow{ }^{5} \mathrm{D}_{+}\right)$that exactly matches the laser frequency. It may be possible to use the ligand-assisted mechanism in combination with laser excitation to overcome the chemical equilibrium problems. It should be possible to achieve exceptionally low limits of detection for these species by SPF.

The spectra of $\mathrm{Ce}^{3+}$ on the ion-exchange film are shown in figure 10. The emission spectrum is in close agreement with that reported in the literature for solution species (ref. 23). The solution absorbance spectrum agrees closely with the spectra found in reference 23 except in the 200 to $250 \mathrm{~nm}$ region where the solution blank absorbs strongly. The excitation spectrum shown in figure 10 is the absorption spectrum of the $\mathrm{Ce}^{3+}$ species free of the solution blank. since the IEM film background is negligible in this region. In the study presented in reference 23 , it was demonstrated that $\mathrm{Ce}^{3+}$ could be determined by fluorometry in the presence of a large excess of $\mathrm{Ce}^{\mathrm{st}}$ to an accuracy of around \pm 10 percent, which implies that the same should be true for spectrofluorometry on IEM films.

\section{CONCLUSIONS}

It has been demonstrated that the use of this new ion-exchange film greatly facilitates the SPF technique. This ion-exchange material is very resistant to fouling by $\mathrm{Ca}^{2+}$. has high capacity, is easy to work with in solution. and easily mounts for spectral analysis. The films can be stored to serve as a record or for future reevaluation. Drawbacks to its use include slow uptake kinetics and the need for fluorescence instrumentation capable of temporal discrimination to produce high-quality spectra free of background fluorescence.

\section{REFERENCES}

1. C.M. Hill, K.W. Street, W.H. Philipp. and S.P. Tanner, Anal. Lett. 27, No. 13, 2589 (1994).

2. W.H. Philipp, C.E. May, and L-C. Hsu, "New Ion-Exchange Membranes" NASA TM-81670 (1980).

3. W.H. Philipp and C.E. May, "Kinetics of Copper Ion Absorption by Cross-Linked Calcium Polyacrylate Membranes" NASA TM-83052 (1983).

4. C.E. May and W.H. Philipp, "Ion Exchange Selectivity for Cross-Linked Polyacrylic Acid" NASA TM-83427 (1983).

5. F. Capitan. E. Manzano, A. Navalon, J.L. Vilchez, and L.F. Capitan-Vallvey, Analyst 114, 969 (1989).

6. F. Capitan, E. Manzano, J.L. Vilchez, and L.F. Capitan-Vallvey, Anal. Sci. 5, 549 (1989).

7. F. Capitan, A. Navalon. J.L. Vilchez, and L.F. Capitan-Vallvey, Talanta 37, 193 (1990).

8. F. Capitan, J.P. de Gracia, A. Navalon. L.F. Capitan-Vallvey, and J.L. Vilchez. Analyst 115. 849 (1990).

9. F. Capitan, E. Manzano, A. Navalon. J.L. Vilchez, and L.F. Capitan-Vallvey, Talanta 39, 21 (1992).

10. F. Capitan, G. Sanchez-Palencia. A. Navalon, L.F. Capitan-Vallvey, and J.L. Vilchez, Anal. Chim. Acta 259. 345 (1992).

11. J.L. Vilchez, A. Navalon. R. Avidad, T. Garcia-Lopez, and L.F. Capitan-Vallvey, Analyst 118. 303 (1993). 
12. S.V. Beltyukova, G.M. Balamtsarashvili, and T.B. Kravchenko, Analyst 117, 807 (1992).

13. S.B. Meshkova, Z.M. Topilova, and G.I. Gerasimenko, Zh. Anal. Khim 48. 65 (1993).

14. W.H. Philipp and K.W. Street, U.S. Patent 5,371,110 (1994).

15. K.A. Murray, E. Gonzalez, R.B. Gregory, and K.W. Street, Appl. Spectr. 43, 351 (1989).

16. J.P. Young, G.M. Murray, D.D. Ensor, and D.O. Vick, Appl. Spectr. 45, 134 (1991).

17. W.D. Horrocks and D.R. Sudnick, Acc. Chem. Res. 14, 382 (1981).

18. T. Kimura, Y. Kato, and G.R. Choppin, "Hydration Studies of Lanthanide (III) and Actinide (III) Ions by Laser-Induced Fluorescence Spectroscopy (LIF)" Recent Prog. Actinide Sep. Chem Proc. WASC '94, 149 (1997).

19. S.P. Tanner and K.W. Street. unpublished data.

20. R.M. Rush, J.S. Johnson, and K.A. Kraus, Inorg. Chem. 1, 378 (1962).

21. R.M. Rush and J.S. Johnson. J. Phys. Chem. 67, 821 (1963).

22. G.H. Schenk, "Absorption of Light and Ultraviolet Radiation: Fluorescence and Phosphorescence Emission" (Allyn and Bacon. Inc. Boston, MA, 1973) p. 232.

23. W.A. Armstrong. D.W. Grant, and W.G. Humphreys, Anal. Chem. 35, 1300 (1963).

\begin{tabular}{|c|c|c|c|}
\hline \multicolumn{4}{|c|}{$\begin{array}{l}\text { TABLE I.-CALIBRATION CURVES FOR Gd (II } \\
\text { USING SIGNAL NORMALIZED TO Tb (III) } \\
\text { PEAK INTENSITY. }\end{array}$} \\
\hline $\begin{array}{c}\text { Tb (III) emission } \\
\text { peak used. } \\
\text { nm }\end{array}$ & $\begin{array}{c}\text { Slope. } \\
\text { Intensity } \\
\text { Ratio/ } \\
\text { ppm Gd }\end{array}$ & Intercept & $\begin{array}{l}\text { Correlation } \\
\text { coefficient }\end{array}$ \\
\hline 545 & 0.19 & -0.08 & 0.994 \\
\hline 488 & 0.38 & -0.20 & 0.999994 \\
\hline
\end{tabular}

TABLE II -RECOVERY OF METALS FROM SOLUTION BY IEM FILM

\begin{tabular}{|c|c|c|c|}
\hline Metal & $\begin{array}{c}\text { Initial concentration. } \\
\mathrm{mg} / \mathrm{L}\end{array}$ & $\begin{array}{c}\text { Percent removed by } \\
100 \mathrm{mg} \text { IEM }\end{array}$ & $\mathrm{pH}$ \\
\hline U(VI) & 15.2 & 68 & 6.3 \\
& 15.2 & 78 & 6.6 \\
$\mathrm{Ce}(\mathrm{III})$ & 1.0 & 80 & 6.6 \\
Eu(III) & 14.2 & $>99$ & 7.0 \\
$\mathrm{Gd}(\mathrm{III})$ & 15.6 & 96 & 6.9 \\
$\mathrm{~Tb}(\mathrm{III})$ & 13.4 & $>99$ & 7.0 \\
\hline
\end{tabular}

As UO ${ }_{2}^{2 *}$. dimers, hydroxy complexes, etc

${ }^{\circ} 96 \%$ U(VI) recovered from film by acid stripping. 


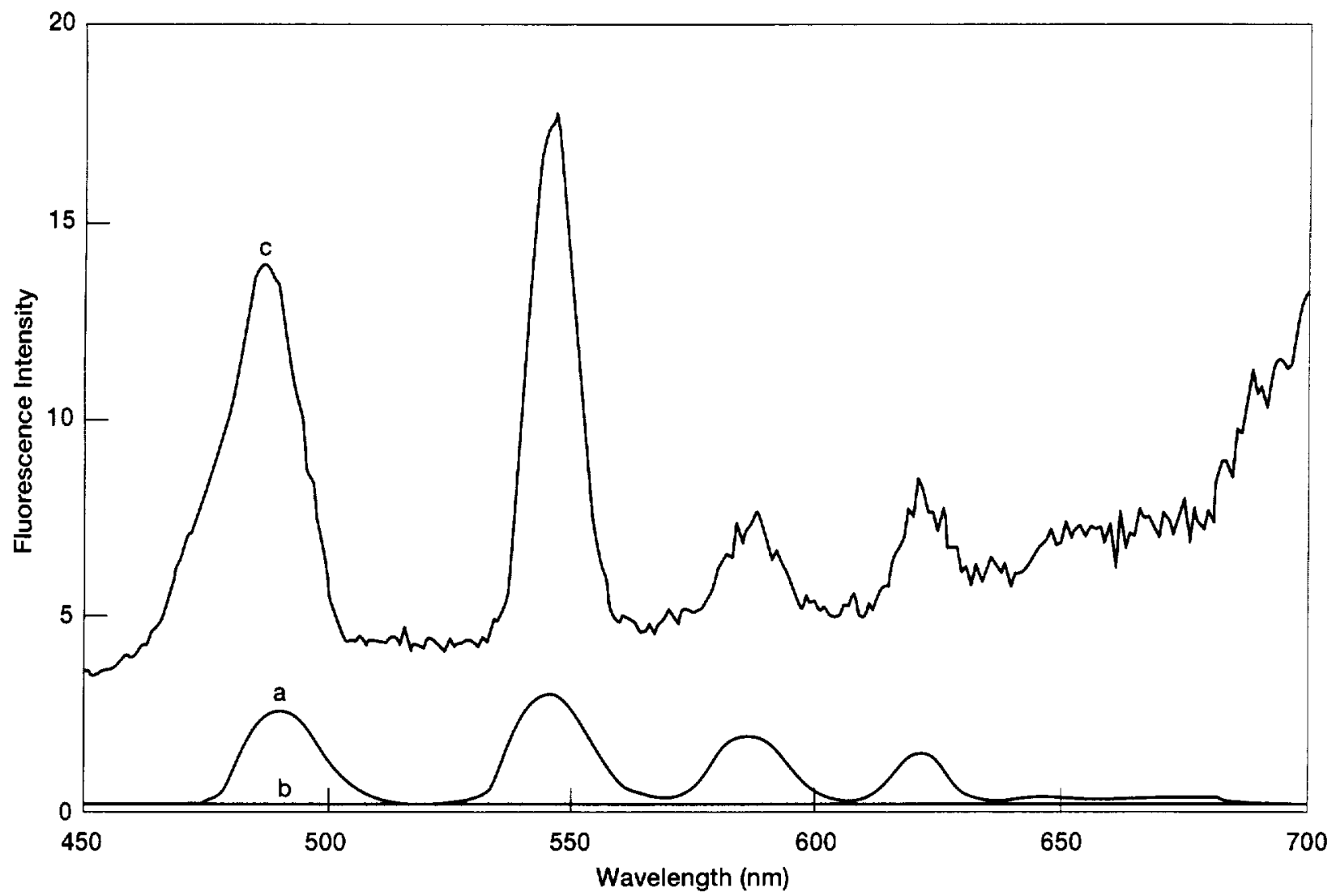

Figure 1.-Comparison of spectra for $\mathrm{Tb}^{3+}$ in solution to $\mathrm{Tb}^{3+}$ on IEM film. (a) $10 \mathrm{mg} / \mathrm{Ib}$ (III) in solution, (b) $10 \mu \mathrm{g} / \mathrm{l}$ $\mathrm{Tb}^{3+}$ in solution, and (c) IEM film, $75 \mathrm{mg}$, equilibrated with 1.0 liter of $10 \mu \mathrm{g} / \mathrm{T} \mathrm{Tb^{3+ }}$ standard. All spectra recorded on an Aminco AB 2 Luminescence Spectrometer and excitation at $240 \mathrm{~nm}$.

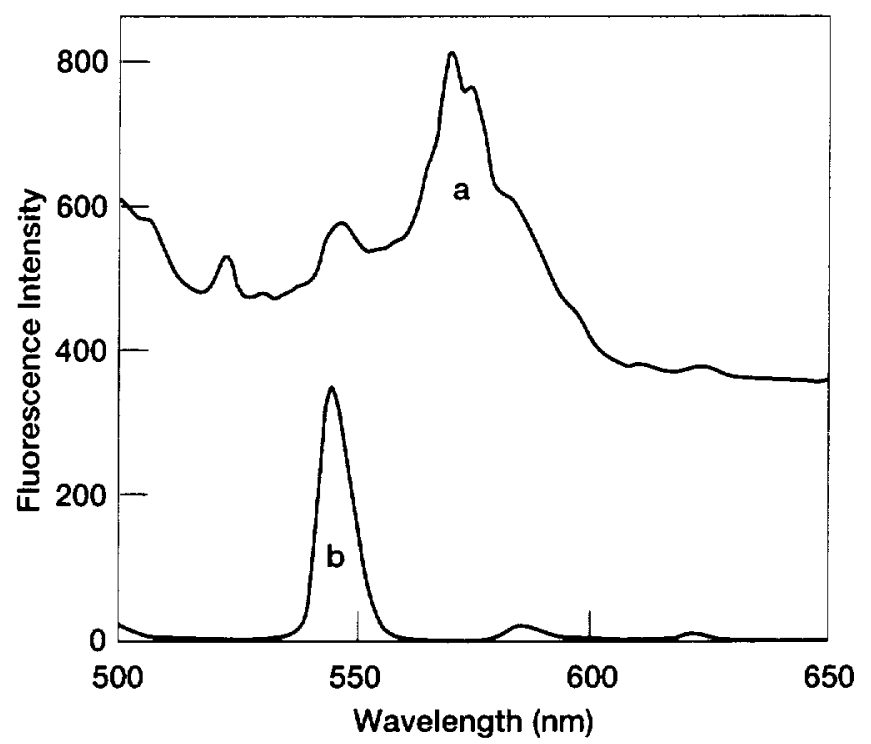

Figure 2.-Luminescence spectra of $\mathrm{Tb}^{3+}$ on IEM film.

(a) Fluorescence mode and (b) phosphorescence mode with $0.1 \mathrm{~ms}$ delay and $1.0 \mathrm{~ms}$ gate. $60 \mathrm{mg}$ IEM equilibrated with $100 \mathrm{ml} 15 \mathrm{mg} / \mathrm{l} \mathrm{Tb}$ standard. All spectra recorded on a Perkin-Elmer Model LS-50b spectrofluorometer using 5-nm excitation and emission slits with a front surface sample attachment and excitation at $375 \mathrm{~nm}$. 


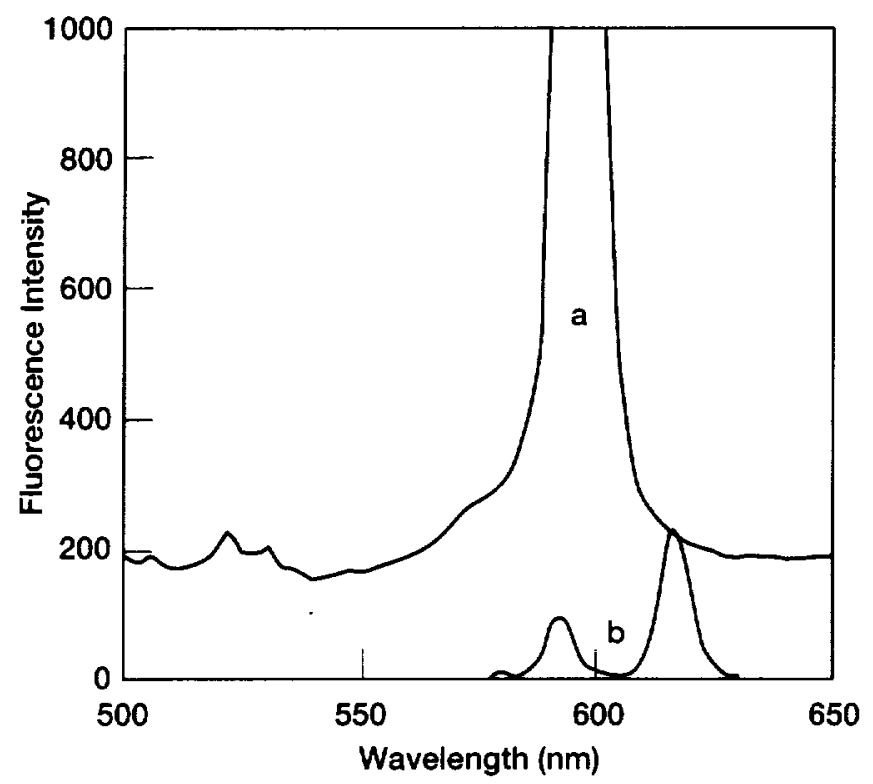

Figure 3.-Luminescence spectra of $\mathrm{Eu}^{3+}$ on IEM film. (a) Fluorescence mode and (b) phosphorescence mode with $0.1 \mathrm{~ms}$ delay and $1.0 \mathrm{~ms}$ gate. $60 \mathrm{mg}$ IEM equilibrated with $100 \mathrm{ml}$ of $15 \mathrm{mg} / \mathrm{l} \mathrm{Eu}$ standard. All spectra recorded on a Perkin-Elmer Model LS-50b spectrofluorometer using 5-nm excitation and emission slits with a front surface sample attachment and excitation at $395 \mathrm{~nm}$.

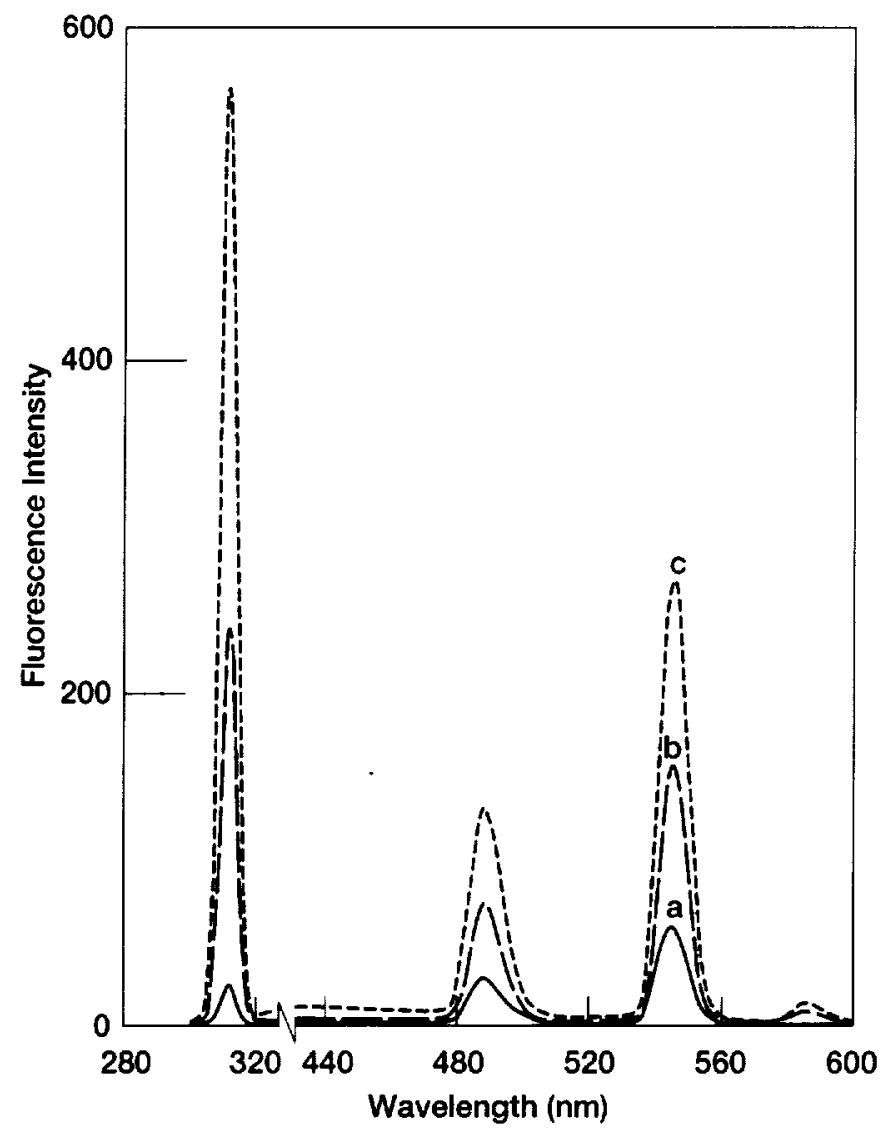

Figure 4.-Luminescence spectra of $\mathrm{Gd}^{3+}$ and $\mathrm{Tb}^{3+}$ on IEM film. (a) $3 \mathrm{mg} / \mathrm{l} \mathrm{Gd}$ and $5 \mathrm{mg} / \mathrm{l} \mathrm{Tb}$, (b) $9 \mathrm{mg} / \mathrm{l} \mathrm{Gd}$ and 5 $\mathrm{mg} / \mathrm{Tb}$, and (c) $12 \mathrm{mg} / \mathrm{l} \mathrm{Gd}$ and $5 \mathrm{mg} / \mathrm{l} \mathrm{Tb}$. All films, $75 \mathrm{mg}$, equilibrated with $200 \mathrm{ml}$ standard at pH 5.5. All spectra recorded in phosphorescence mode with $0.2 \mathrm{~ms}$ delay and $1.0 \mathrm{~ms}$ gate on a Perkin-Elmer Model LS-50b spectrofluorometer using 5-nm excitation and emission slits with a front surface sample attachment and excitation at $272 \mathrm{~nm}$. 


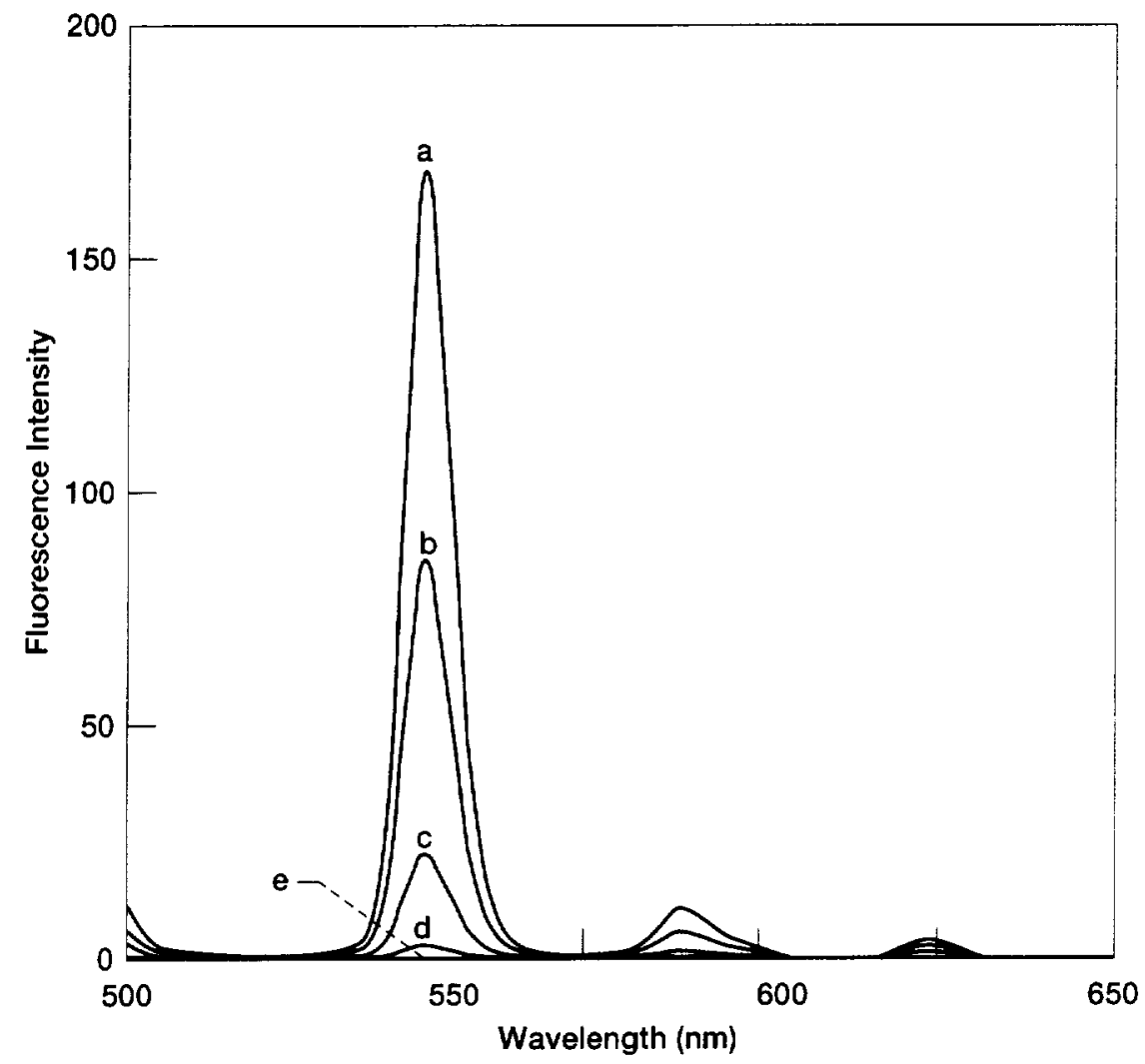

Figure 5.-Luminescence spectra of $\mathrm{Tb}^{3+}$ on IEM film. (a) $200 \mu \mathrm{g} / \mathrm{l}$, (b) $75 \mu \mathrm{g} /$, (c) $25 \mu \mathrm{g} / \mathrm{l}$, (d) $10 \mu \mathrm{g} / \mathrm{l}$, and (e) 5 or $0 \mu \mathrm{g} / \mathrm{l}$. Phosphorescence mode with $0.1 \mathrm{~ms}$ delay and $1.0 \mathrm{~ms}$ gate. $60 \mathrm{mg}$ IEM equilibrated with standard at $\mathrm{pH}$ 6.5. All spectra recorded on a Perkin-Elmer Model LS-50b spectrofluorometer using 5-nm excitation and emission slits with a front surface sample attachment and excitation at $240 \mathrm{~nm}$. 


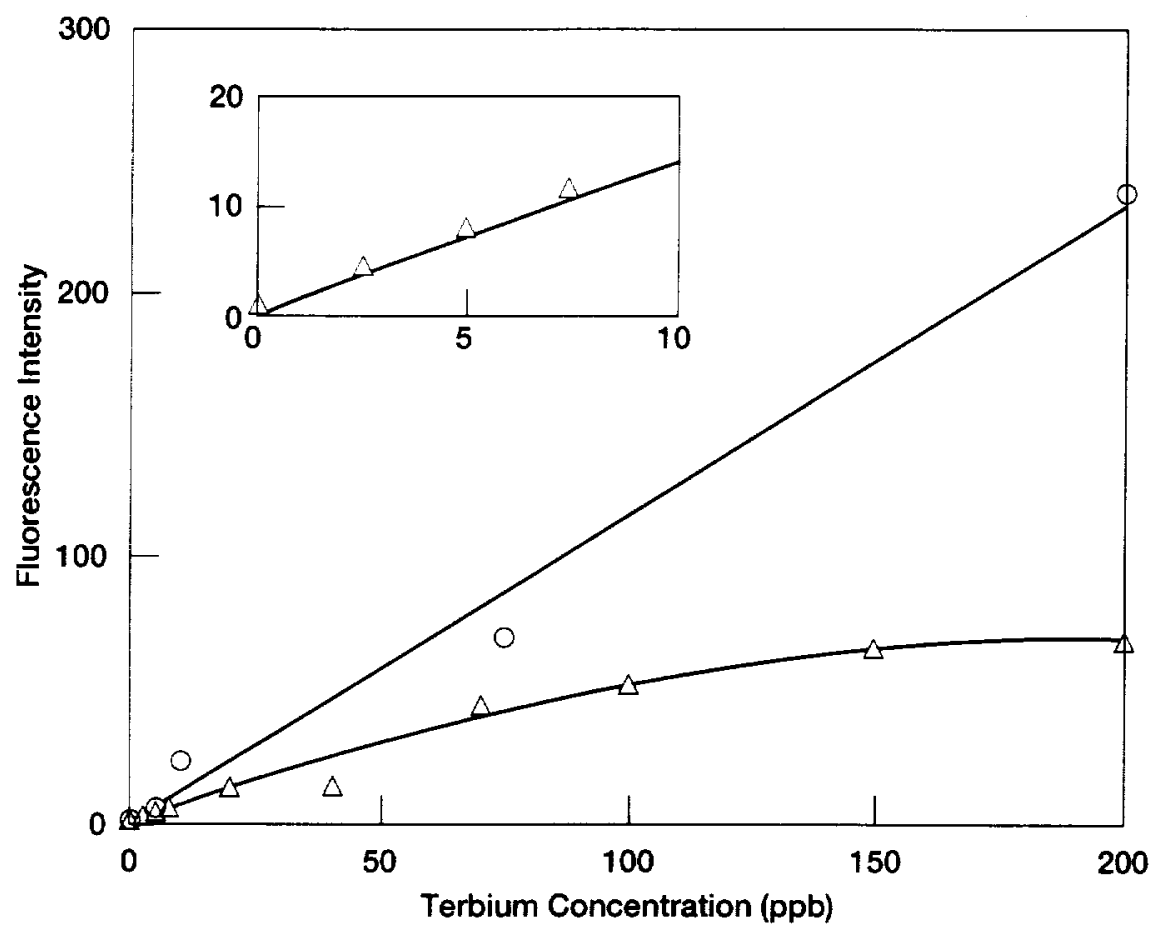

Figure 6.-Calibration curves obtained from $545-\mathrm{nm}$ emission intensities of $(0) \mathrm{Tb}^{3+}$ and $(\Delta) \mathrm{Tb}^{3+}$-o-phenanthroline complex on IEM film. Insert is expansion of the 0-7.5 $\mu \mathrm{g} / \mathrm{l}$ portion of the $\mathrm{Tb}^{3+}-0$-phenanthroline complex curve. All spectra recorded on an Aminco AB 2 Luminescence Spectrometer. 


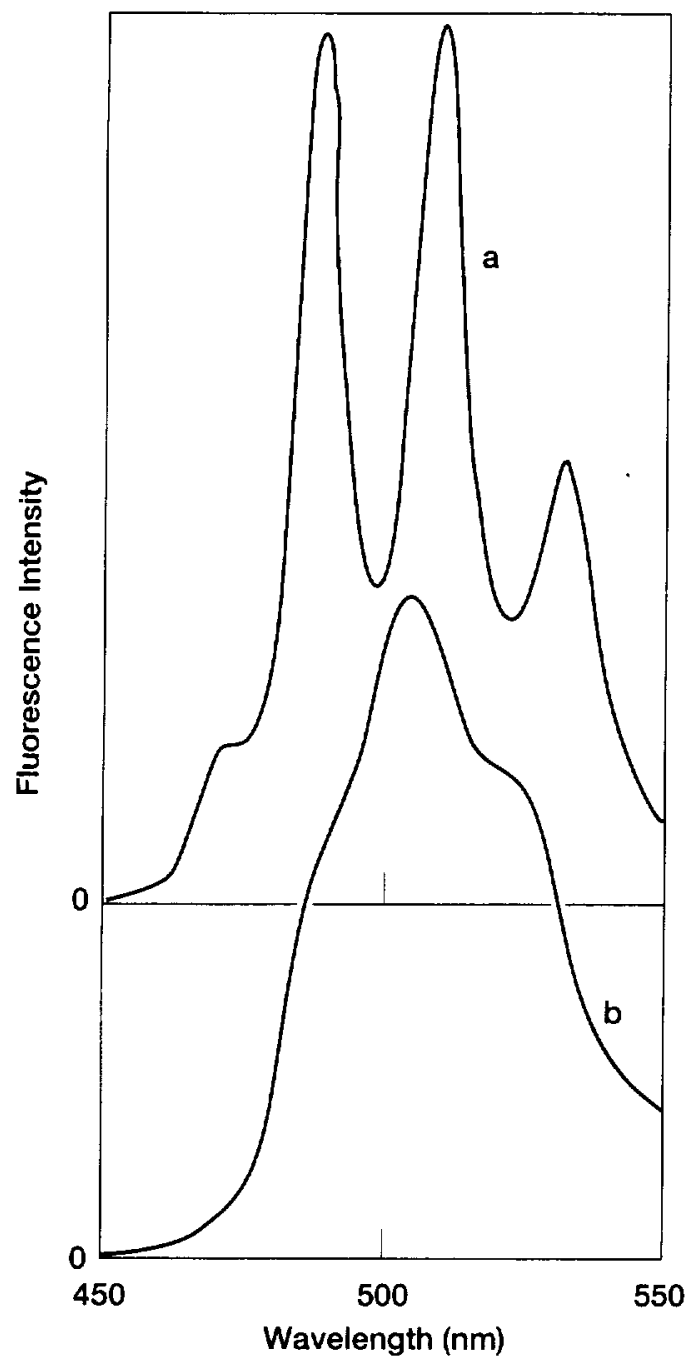

Figure 7.-Fluorescence spectra of U(VI) in solution. (a) $\mathrm{U}(\mathrm{VI})$ in phosphoric-sulfuric acid medium (see ref. 22 for details) and (b) $\mathrm{UO}_{2}{ }^{2+}$, dimers, hydroxy complexes, etc. at $\mathrm{pH}$ 6.6. All spectra recorded on a Baird Atomic model FC 100 Fluoricord Spectrofluorometer with excitation at $350 \mathrm{~nm}$.

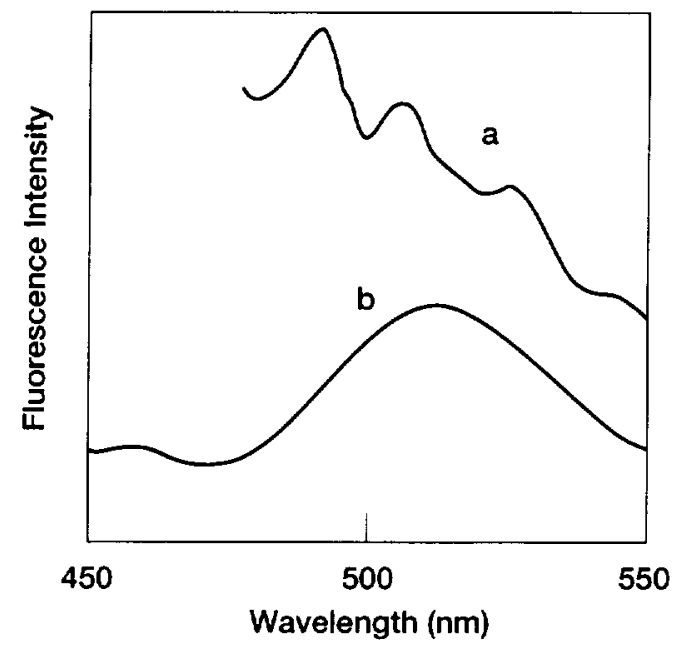

Figure 8.-Fluorescence spectra of U(VI) in IEM film. (a) $1 \mathrm{mg} / \mathrm{U} \mathrm{U}(\mathrm{VI})$ and (b) $15 \mathrm{mg} / \mathrm{I} U(\mathrm{VI}) .50 \mathrm{mg}$ IEM equilibrated with $200 \mathrm{ml}$ standard at $\mathrm{pH}$ 6.6. All spectra recorded on a Baird Atomic model FC 100 Fluoricord Spectrofluorometer with excitation at $350 \mathrm{~nm}$. 


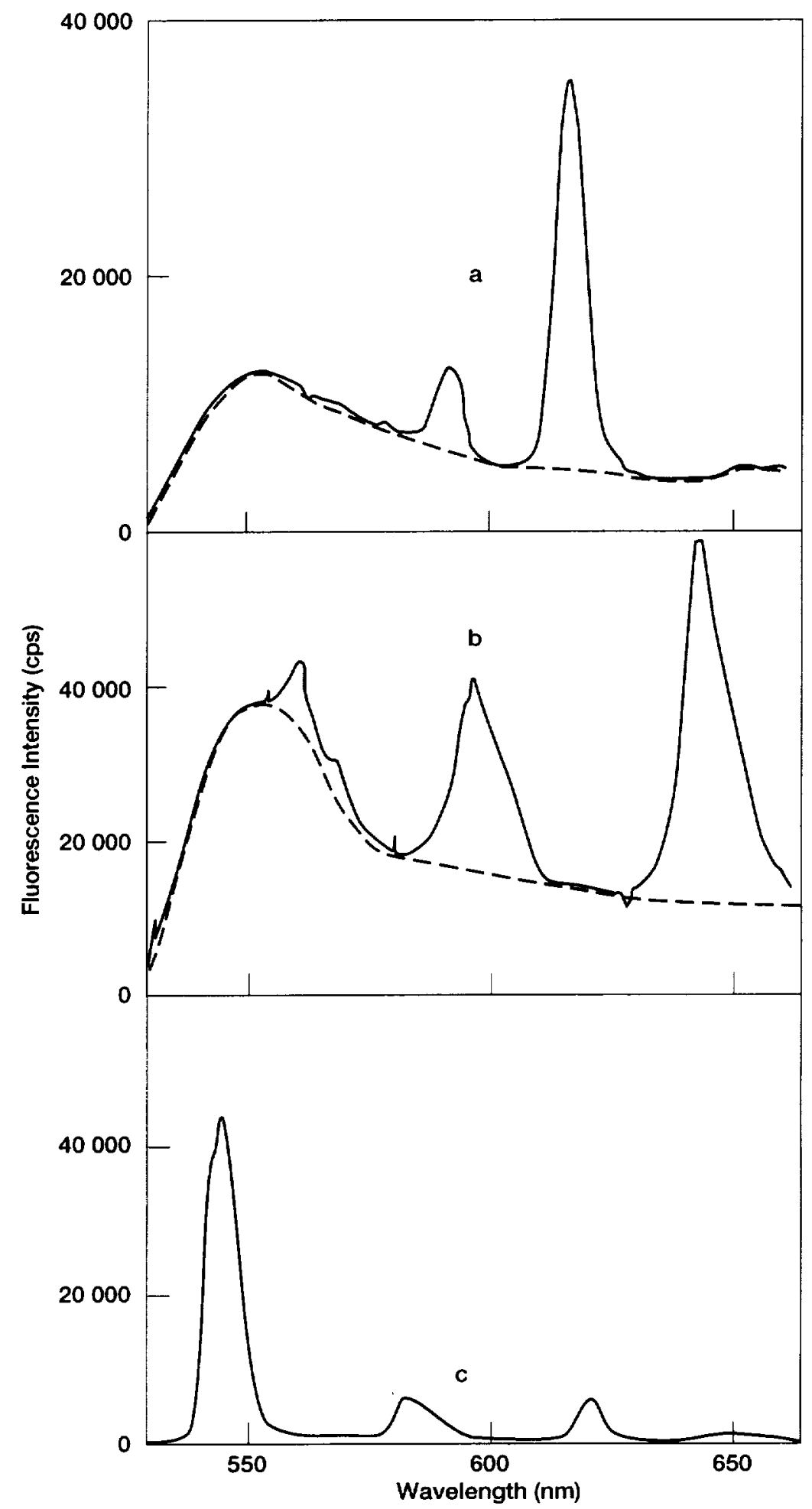

Figure 9.-Fluorescence spectra of lanthanides on IEM film. (a) $\mathrm{Eu}^{3+}$, (b) $\mathrm{Sm}^{3+}$, and (c) $\mathrm{Tb}^{3+}$. Dashed line represents film blank. All spectra recorded on a laser luminescence spectrometer with $C C D$ detector. 


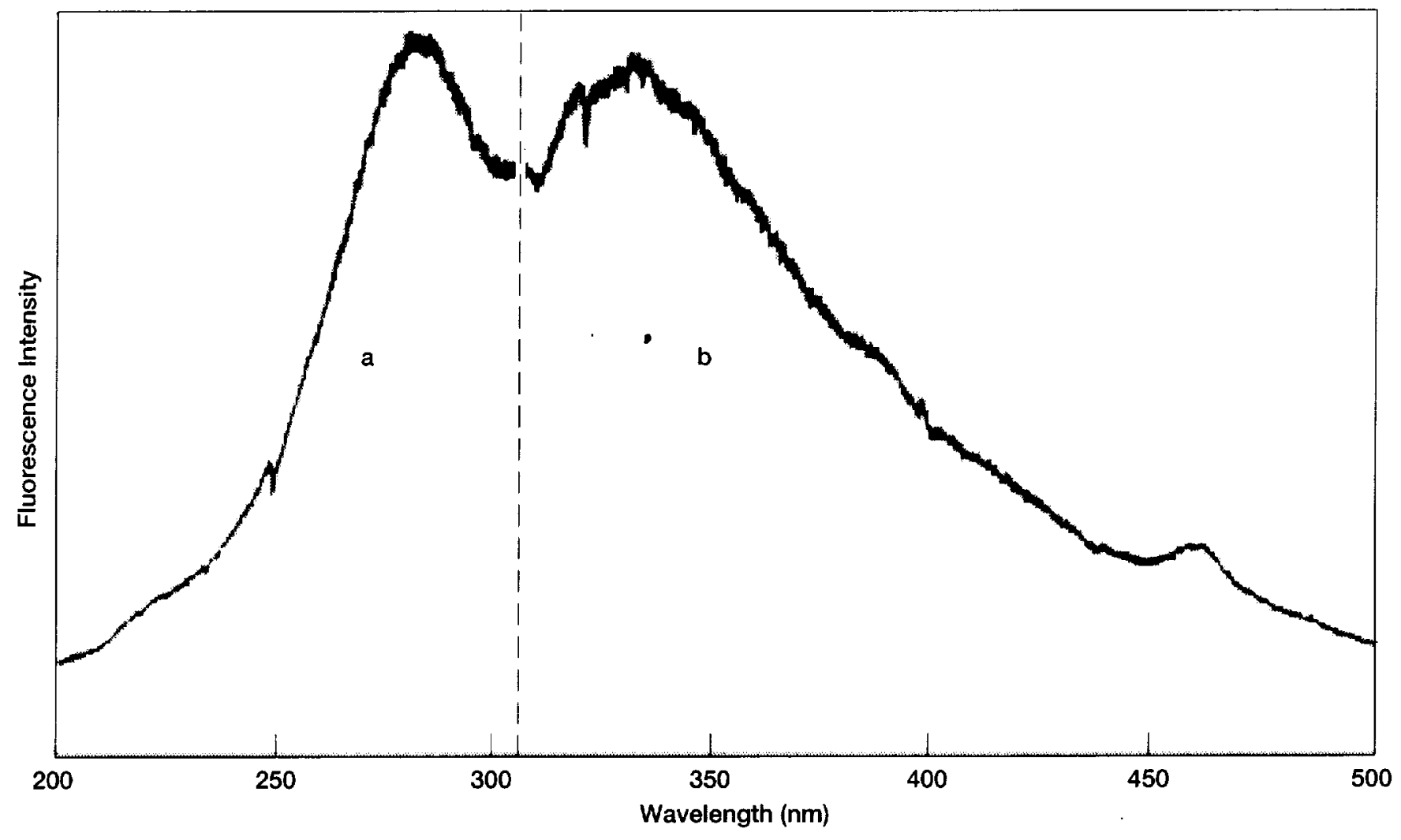

Figure 10.-Fluorescence excitation and emission spectra of $\mathrm{Ce}^{3+}$ on IEM film. (a) Excitation spectrum with emission fixed at $330 \mathrm{~nm}$ and (b) emission spectrum with excitation at $283 \mathrm{~nm}$. Spectra recorded on a Baird Atomic Model FC 100 Fluoricord Spectrofluorometer. Film equilibrated with $200 \mathrm{ml}$ of $15 \mathrm{mg} / \mathrm{l}$ standard at $\mathrm{pH} 5.8$. 


\begin{tabular}{|c|c|c|c|}
\hline \multicolumn{3}{|c|}{ REPORT DOCUMENTATION PAGE } & $\begin{array}{l}\text { Form Approved } \\
\text { OMB No. 0704-0188 }\end{array}$ \\
\hline \multicolumn{4}{|c|}{ 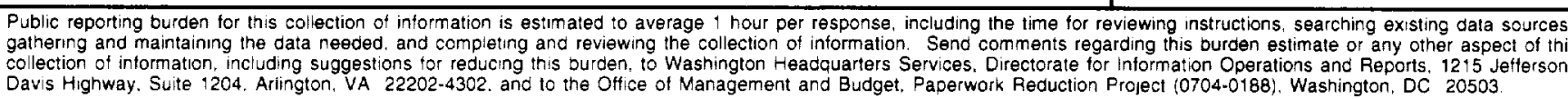 } \\
\hline 1. AGENCY USE ONLY (Leave blank) & $\begin{array}{l}\text { 2. REPORT DATE } \\
\text { December } 1999\end{array}$ & & $\begin{array}{l}\text { JD DATES COVERED } \\
\text { echnical Memorandum }\end{array}$ \\
\hline $\begin{array}{l}\text { 4. TITLE AND SUBTITLE } \\
\text { Solid Phase Luminescence o }\end{array}$ & veral Rare Earth Ions on & Solid Phase Luminescence of Several Rare Earth Ions on Ion Exchange Films & 5. FUNDING NUMBERS \\
\hline $\begin{array}{l}\text { 6. AUTHOR(S) } \\
\text { Stephen P. Tanner and Kenne }\end{array}$ & N. Street & & WU $-910--30-11-00$ \\
\hline $\begin{array}{l}\text { 7. PERFORMING ORGANIZATION NA } \\
\text { National Aeronautics and Sp } \\
\text { John H. Glenn Research Cen } \\
\text { Cleveland. Ohio } 44135-315\end{array}$ & $\begin{array}{l}\text { AND ADDRESS(ES) } \\
\text { Administration } \\
\text { Lewis Field }\end{array}$ & & $\begin{array}{l}\text { 8. PEFFORMING ORGANIZATION } \\
\text { REPORT NUMBER } \\
\text { E- } 11450\end{array}$ \\
\hline $\begin{array}{l}\text { 9. SPONSORING/MONITORING AGEN } \\
\text { National Aeronautics and Sp } \\
\text { Washington. DC } 20546-00\end{array}$ & $\begin{array}{l}\text { VAME(S) AND ADDRESS(ES) } \\
\text { Adninistration }\end{array}$ & & $\begin{array}{l}\text { 10. SPONSORING/MONITORING } \\
\text { AGENCY REPORT NUMBER } \\
\text { NASA TM-1999-208838 }\end{array}$ \\
\hline
\end{tabular}

Stephen P. Tanner, University of West Florida, Department of Chemistry, 11000 University Parkway. Pensacola, Florida 32514: Kenneth W. Street. Jr., NASA Glenn Research Center. Responsible person. Kenneth W. Street. Jr., organization code 5140, (216) 433-5032.

12a. DISTRIBUTION/AVAILABILITY STATEMENT

12b. DISTRIBUTION CODE

Unclassified - Unlimited

Subject Category: 25

Distribution: Nonstandard

This publication is available from the NASA Center for AeroSpace Information. (301) 621-0390.

13. ABSTRACT (Maximum 200 words)

The development and characterization of a novel ion-exchange film for solid-phase fluorometry and phosphorimetry is reported. This new cation-exchange material is suitable for spectroscopic applications in the ultraviolet and visible regions. It is advantageous because it, as a single entity. is easily recovered from solution and mounted in the spectro fluorometers. After preconcentration on the film, the luminescence intensity of lanthanide ions is several orders of magnitude greater than that of the corresponding solution, depending on the volume of solution and the amount of film. This procedure allows emission spectral measurements and determination of lanthanide ions at solution concentrations of $<5 \mu \mathrm{g} / \mathrm{L}$. The film may be stored for subsequent reuse or as a permanent record of the analysis. The major drawback to the use of the film is slow uptake of analyte due to diffusion limitations.

\section{SUBJECT TERMS}

Solid phase fluorometry; Lanthanide; Ion-exchange film; Luminescence

15. NUMBER OF PAGES 19

16. PRICE CODE

17. SECURITY CLASSIFICATION
OF REPORT
Unclassified

16. SECURITY CLASSIFICATION
OF THIS PAGE
Unclassified
19. SECURITY CLASSIFICATION OF ABSTRACT Unclassified

